\title{
STURMIAN COMPARISON METHOD: THE VERSION FOR FIRST ORDER NEUTRAL DIFFERENTIAL EQUATIONS
}

\author{
Y. Domshlak, G. KVINIKADZE AND I. P. StAVROUlaKIS
}

Abstract. In this paper the Sturmian Comparison Method is developed for the first order neutral differential equation of the type

$$
l(y):=[y(t+1)-P(t) y(t)]^{\prime}+Q(t) y(t+1-\sigma)=0, \quad \sigma \geqslant 0 .
$$

Using this method, a general theorem is proved on the location of zeros of (1), which is then applied to obtain two concrete results. The first one of them turns out to be the best possible in the case where $P$ and $Q$ are constants. The second one is concerned, for the first time, with the oscillation theory of first order neutral differential equations, in the case where the coefficient $Q(t)$ is oscillatory.

Mathematics subject classification (2000): 34K11, 34K40.

Key words and phrases: Oscilation properties, neutral equations, location of zeros.

\section{REFERENCES}

[1] L. Erbe, Q. Kong, B. G. ZHANG, Oscillation Theory for Functional Differential Equations, Marcel Dekker, 1994.

[2] Y. DOMSHLAK, Sturm-like comparison theorems for the first and second order delay differential equations (Russian), Ukr. Math. Zh. 1982, No. 2, 153-163.

[3] Y. DOMSHLAK, Sturmian comparison method in investigations of differential operator equations (Russian), Baku, Elm, 1986.

[4] Y. DOMSHLAK, Location of the zeros and oscillation of solutions of the first order neutral differential equations, Izv. Acad. Sci. Azerbaijan, No. 2 (1984) 24-30.

[5] Y. DOMSHLAK AND L. SHEIKHZAMANOVA, Location of the zeros of solutions of the second order neutral differential equations, Izv. Acad. Sci. Azerbaijan, No. 4 (1985) 23-28.

[6] D. BAINOV AND D. MisHEV, Oscillation theory of neutral differential equations with delay, Adam Hilger 1991. 